\title{
Analysis of the influence of the cutting edge geometry on parameters of the perforation process for conveyor and transmission belts
}

\author{
Dominik Wojtkowiak ${ }^{1,}{ }^{*}$, Krzysztof Talaśka ${ }^{1}$, Ireneusz Malujda ${ }^{1}$, Grzegorz Domek ${ }^{2}$ \\ ${ }^{1}$ Chair of Basics of Machine Design, Poznan University of Technology, Piotrowo 3, 60-965 Poznan, \\ Poland \\ ${ }^{2}$ Faculty of Mathematics, Physics \& Technical Sciences, Kazimierz Wielki University in Bydgoszcz, \\ 85-092 Bydgoszcz, Poland
}

\begin{abstract}
Perforated belts, which are used in vacuum conveyor belts, can have significantly different mechanical properties like strength and elasticity due to a variety of used materials and can have different thickness from very thin $(0,7 \mathrm{~mm})$ to thick belts $(6 \mathrm{~mm})$. In order to design a complex machine for mechanical perforation, which can perforate whole range of belts, it is necessary to research the influence of the cutting edge geometry on the parameters of the perforation process. Three most important parameters, which describe the perforation process are the cutting force, the velocity and the temperature of the piercing punch. The results presented in this paper consider two different types of punching (a piercing punch with the punching die or with the reducer plate) and different cutting edge directions, angles, diameters and material properties. Test were made for different groups of composites belts - with polyurethane and polyester fabric, polyamide core or aramidfibre reinforced polymers. The main goal of this research is to specify effective tools and parameters of the perforation process for each group of composites belts.
\end{abstract}

Keywords: conveyor belts, timing belts, punching, polymer composites, perforation.

\section{Introduction}

Conveyor belts are used to transport goods from one point to another and most commonly are made as multilayer composite flat belts. Basically there are two main types of conveyor belts: strong rigid belts with polyamide or aramid cord traction layer (Fig. 1a) and light elastic belts, which are made of polyurethane, polyester fabric or PVC (Fig. 1b) [1-3].

Timing belts (Fig. 1c) are toothed belts, which are used to synchronize a rotation of two toothed wheels or to convert a rotary motion of the shaft into a reciprocating motion of the carriage. Timing belts are made of polyurethane or rubber as a base material with tension member, which can be made of either aramid or glass fibers or even steel cord for applications with higher loads. In order to gain specific properties (e.g. lower friction, silent

\footnotetext{
*Corresponding author: dominik.wojtkowiak@put.poznan.pl

Reviewers: Milan Vaško, Ján Vavro
} 
operation) both sides of the timing belt can be coated with various materials and structures [4-6].

Vacuum belts (Fig. 1d) are a highly elegant solution to transport light products, such as paper, foil, carton etc., as individual items due to the fact that their low mass makes them unsuitable for conveying by friction. That is why vacuum belt conveyors are commonly used in paper manufacturing and converting, printing machines, food industry, pharmaceutical industry and as conveyors for material handling. This type of belts can be made from both flat and toothed belts by using proper modifications, which are the perforation and the milling. During the perforation process cylindrical holes, which are used to suck the air through the belt, are machined. Milling can be used to create slots in order to increase suction surface area or to create flat suction track by machining part of teeth [4-6].

a)

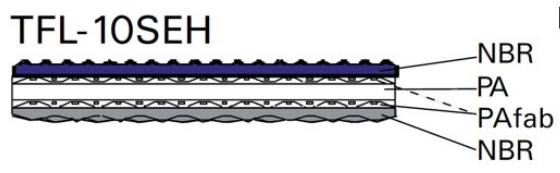

c)

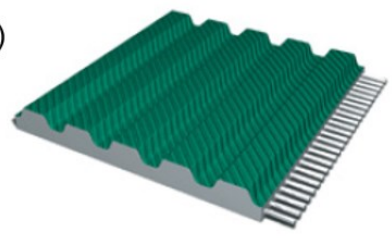

b)

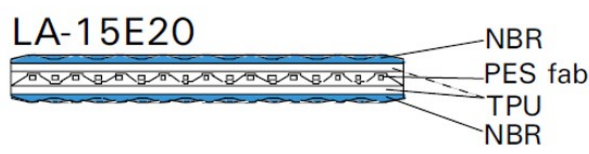

d)

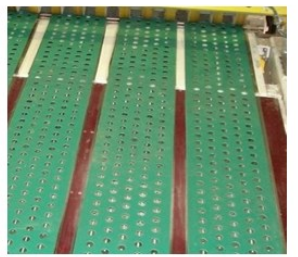

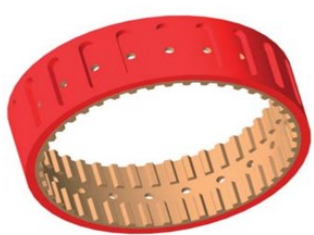

Fig. 1. Conveyor, timing and vacuum belts: a) Nitta PolyBelt with polyamide traction layer b) Nitta PolySprint with polyester fabric and polyurethane, c) BRECO polyurethane timing belt with steel tension member and polyamide fabric coating, d) vacuum belts (Norditec and NK Technics)

The most important stage of a vacuum belt manufacturing process is perforation. This paper shows the analysis of the influence of the cutting edge geometry, the temperature and the velocity of a piercing punch on the cutting force necessary to perforate a composite belt and on the quality of holes.

\section{Methods of belt perforations}

Basically we can distinguish four different perforation methods, which are suitable for polymer composites: laser or abrasive waterjet cutting (nonmechanical methods) and drilling or punching holes (mechanical methods). Nonmechanical methods have an advantage over the mechanical ones that there is no contact forces and abrasive wear of the tool, however its initial and exploitation cost are much higher [7].

Laser cutting allows to cut precisely very small holes with smooth edges and high speed, but due to the high temperature it may change the properties and lower the strength of a material in heat affected zone (HAZ). Moreover laser cutting may cause thermal deformation such as folding of the coating and delamination, changing belt colour or emitting dangerous substances - during the machining of aramid-fibre reinforced materials large amount of hydrogen cyanide are produced [7-11].

With abrasive waterjet (AWJ) technology it is possible to cut almost all materials, and it gives similar quality of the hole to laser cutting without any thermal deformation, but the velocity of cutting is low and it is necessary to drain water after cutting and dry a belt [7, 10-12]. 
Drilling has an ease of positioning, but increasing temperature during the process may cause thermal deformation and the characteristic load distribution during entering and exiting the material leads to delamination of the composite belt and creating uneven edges of a hole. Most of the disadvantages can be reduced or even eliminated by properly choosing the drilling tool and parameters of the drilling (feed rate, cutting speed), but it must be made for each case individually $[7,13,14]$.

The most suitable method for mass production of perforated belt will be mechanical working using a punching die with a piercing punch, which can cooperate with the piercing die or the reducer plate. Punching is a cheap and simple mechanical machining process, which can be performed with high velocity and low thermal influence on a perforated belt. Holes created by punching can have different contours depending on the shape of a piercing punch. When considering multilayer and fibre-reinforced composites in a punching process, there is a chance that delamination or fibre pull-out may occur, but by choosing proper parameters and tool it can be prevented. There are three basic types of piercing punches: cylindrical with the punching die (Fig. 2a), hollow with the cutting edge towards inside (Fig. 2b) and hollow with the cutting edge towards outside (Fig. 2c) [15-18].

a)

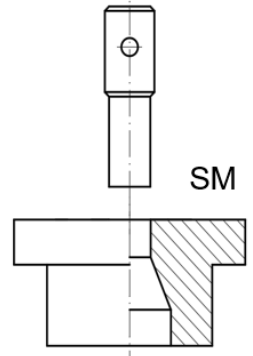

b)

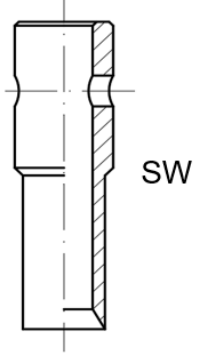

c)

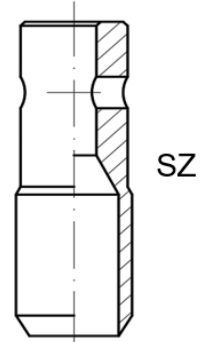

Fig. 2. Basic types of piercing punches: a) piercing punch with the piercing die, b, c) hollow piercing punch which cooperate with the reducer plate with the cutting edge towards inside (b) or outside (c)

\section{Methodology of research}

Perforation research was made by using the designed punching die (Fig. 3) and strength testing machine MTS. The presented construction allows to use different types of piercing punches and heat them up to $200^{\circ} \mathrm{C}$. However preliminary research indicated, that the temperature of the piercing punch higher than $150^{\circ} \mathrm{C}$ causes permanent thermal deformations of the perforated belt. That is why all tests were performed for 4 different temperatures of the working tool: $25^{\circ} \mathrm{C}$ (room temperature), $50^{\circ} \mathrm{C}, 100^{\circ} \mathrm{C}$ and $150^{\circ} \mathrm{C}$. Default value of the velocity of the piercing punch in all tests, except the one where the influence of velocity on the cutting force was checked, was $0,5 \mathrm{~mm} / \mathrm{s}$. During the research, by changing the setting of testing machine, it was possible to measure the cutting force for different (Nitta) belts, cutting edge geometry (outer diameter, angle of the cutting edge and type of a piercing punch), temperature and velocity. The results are presented following the key presented in Fig. 4. 
a)

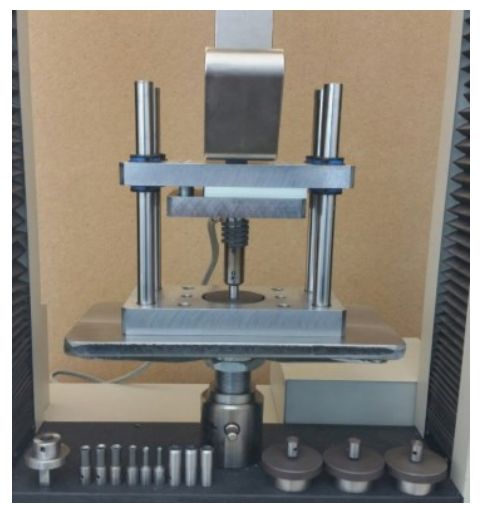

b)

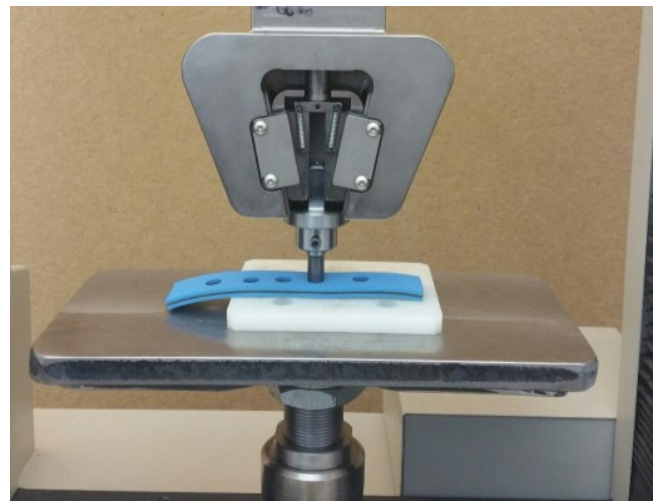

Fig. 3. Punching diees with all used tools during performed tests: a) piercing punch with the piercing die, b) hollow piercing punch which cooperates with the reducer plate

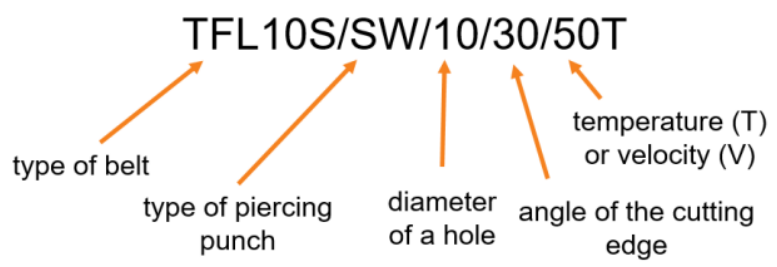

Fig. 4. Key used in signification of performed tests results

\section{Results and discussion}

First series of tests were made in order to determine the influence of the tool geometry on the value and characteristic of the cutting force. Tests were performed with default velocity and room temperature for 7 different piercing punches with diameters of $10 \mathrm{~mm}$ and for two belts, which represent both groups of conveyor belts - strong rigid belt with polyamide core TFL10S and light elastic belt with polyester fabric, as a traction layer LAB12E. Obtained results are presented as a cutting force in a function of a displacement on the charts in Fig. 5 and Fig. 6.

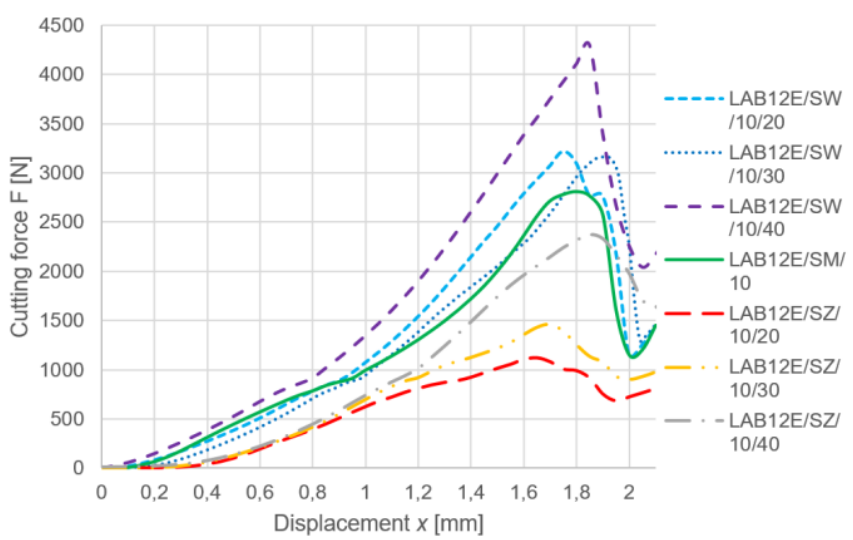

Fig. 5. Cutting force during perforation for different types of tools with diameter of

$10 \mathrm{~mm}$ and various tool angles for PolySprint Nitta LAB12E 


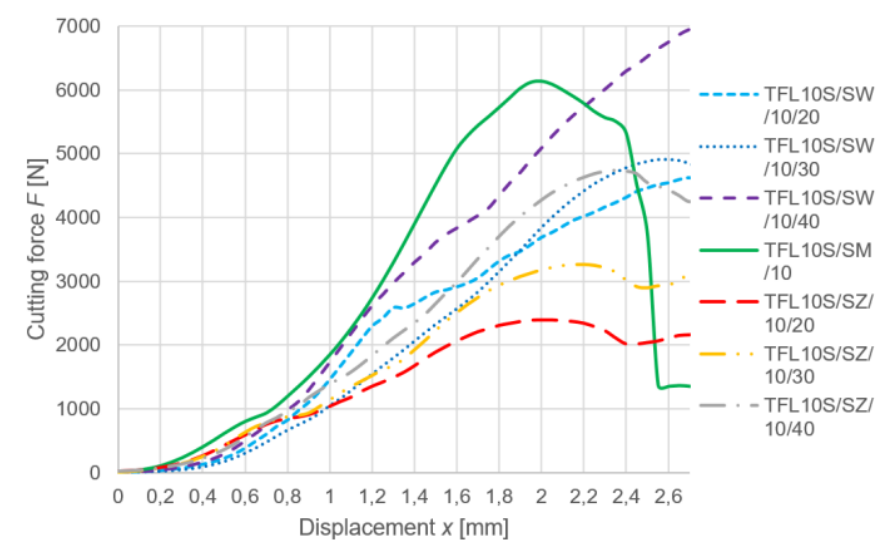

Fig. 6. Cutting force during perforation for different types of tools with diameter of $10 \mathrm{~mm}$ and various tool angles for PolyBelt Nitta TFL10S

By analysing shown characteristics, it is visible that in both cases the lowest amount of the cutting force was used, while perforating with the hollow piercing punch with the cutting edge towards outside (SZ). This phenomenon can be explained by describing the changes of the cutting force during the punching process for each type of the piercing punch. In case of the LAB12E belt (Fig. 5) the main strength depends on the polyester fabric, and this is the reason why there is a sudden drop in the force value at approximately $1,8 \mathrm{~mm}$ of thickness. By comparing SZ and SW types of the piercing punch it is clear that cutting through the fabric is much smoother and needs about 2 times lower force when the cutting edge is towards outside. This is the consequence of the type of stress, which occurs for different types of tools. If we use the SZ piercing punch, scrap must be compressed with the decrease of the inner diameter in a tool, while in the SW piercing punch belt it must be extended with the increase the outer diameter of a tool - inner diameter remains constant. Polyester fabric has an orthogonal properties, which depends on the configuration of the woven in the structures. It is much more elastic in the direction along belt axis, because in normal work conditions the conveyor belt is meant to carry tensile stress.

The piercing punch, which cooperates with the piercing die (SM) is placed in the middle, because in that case the main stress taking place in the perforation process, is the shearing stress. In that case the stage of the perforation process occurring just before the sudden drop of the cutting force, is connected with friction resistance during pushing the material through the channel in the piercing die. In all types of punching additional compression occurs due to the thrust force, which is the effect of the feed of the piercing punch. That is why there is a bending point, characteristically at $0,8-1 \mathrm{~mm}$ of displacement, which corresponds to the elastic-plastic compression model with reinforcement of the material, which was verified during compression tests made on this belt in preliminary tests.

On the other hand, if we observe the results for the strong rigid belt with polyamide film core TFL10S (Fig. 6), we can see a clear fall of the cutting force at the end of the process only for the piercing punch with the piercing die. The main reason for this may be the fact, that the cut through the belt occurs after the rupture of the hard polyamide film structure, which is not as sudden as in polyester fabric. Due to higher resistance and greater compression stress than for the elastic belt, the piercing punch must be plunged deeper into the reducer plate. Due to the similar properties of the core of TFL10S and the reducer plate made of PA6 or PP, the cutting force is reduced slightly or is not reduced at all after finishing the perforation process. The main difference between the belt LAB12E and TFL10S is that the highest value of force is necessary for the piercing punch with the 
piercing die due to higher Young modulus for compression in strong rigid belts. Other relations described for elastic belts correspond with the results for the belt TFL10S.

Another conclusion which can be observed on both charts is that decreasing the tool angle causes the fall of the cutting force, but it is not proportional. That is why the tool angle $30^{\circ}$ can be taken as an effective one, because it is a compromise between the cutting force and the durability of the cutting edge. The obtained results also provide information that proper stress of the belt during the perforation process and the wear of the piercing punch have an effect on the belt perforation, especially when machining elastic conveyor belts. We can see, that regardless of the type of the piercing punch or type of the belt, the perforation process is a really complex issue and many factors have an influence on the cutting force.

The second part of the research was made to determine, if velocity has influence on the cutting force or not. The obtained results are presented in Fig. 7 and Fig. 8. For elastic belts the influence of velocity is insignificant, while for polyamide belts higher speed may reduce the cutting force, but not in a linear way. It is necessary to extend the tests in future research in order to draw more specific conclusions.

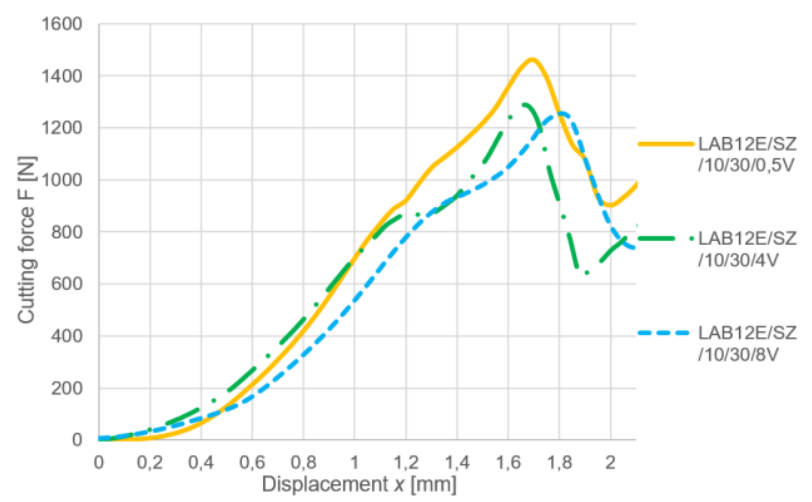

Fig. 7. Comparison of the cutting force during perforation by using the piercing punch with diameter of $10 \mathrm{~mm}$, the tool angle $30^{\circ}$ and the cutting edge towards outside with various perforation velocity for PolySprint Nitta LAB12E

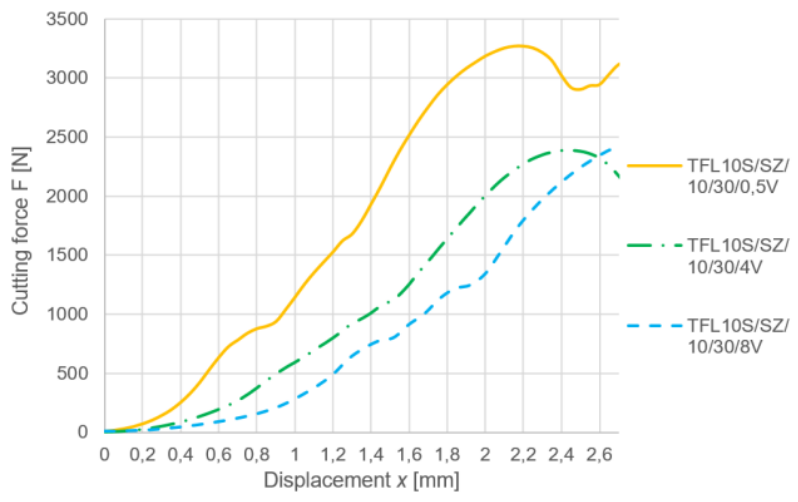

Fig. 8. Comparison of the cutting force during perforation by using the piercing punch with diameter of $10 \mathrm{~mm}$, the tool angle $30^{\circ}$ and the cutting edge towards outside with various perforation velocity for PolyBelt Nitta TFL10S 
During the machining of the polymer composites increased temperature is almost always treated as a disadvantage of the method due some thermal deformation and mechanical properties changes. On the other hand properly controlled heat can be very helpful, as it softens the material, which makes it easier to machine. That is why, it is crucial to determine the influence of the increased temperature on the cutting force in punching of conveyor belts. The obtained results are presented in Fig. 9, 10, 11 and 12.

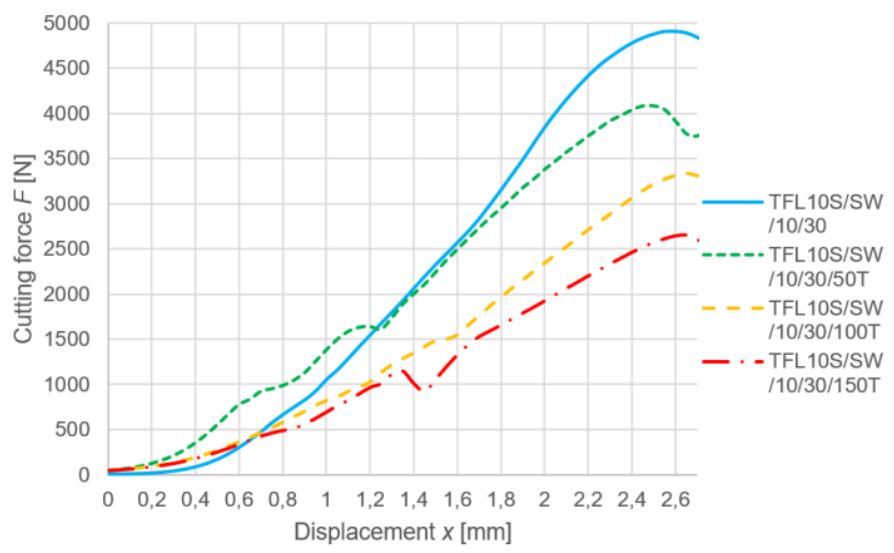

Fig. 9. Comparison of the cutting force during the perforation by using piercing punch with diameter of $10 \mathrm{~mm}$, the tool angle $30^{\circ}$ and the cutting edge towards inside, with various perforation temperature for PolyBelt Nitta TFL10S

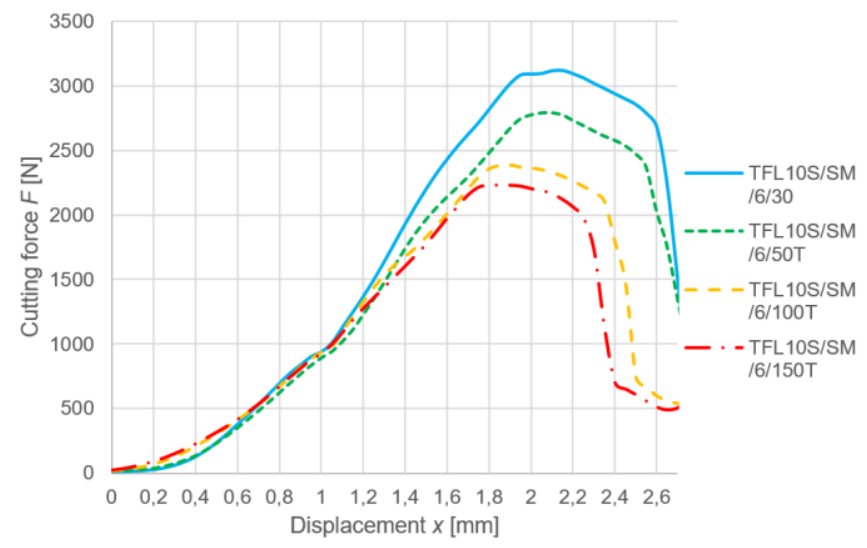

Fig. 10. Comparison of the cutting force during perforation by using the piercing punch with diameter $6 \mathrm{~mm}$ with the punching die, with various perforation temperature for PolyBelt Nitta TFL10S

If we take into account the strong rigid belt TFL10S (Fig 9, 10 and 11), it is visible that increased temperature of the piercing punch can decrease the amount of force necessary to perform perforation of the composite belt. To properly analyse the results punching must be divided into two stages: pure cutting with thrust compression of the belt, and cutting with additional resistance due to axial and transverse compression of the scrap, extension of the belt or friction in the channel of the piercing die. It is visible, that by using the piercing punch with the reducer plate, cutting force is lower already in the first stage, which is connected with penetration into the softened material - it is easier to compress the scrap or extend the belt. On the contrary to that, while using the piercing die differences are visible only in the final stage - it is easier to push softened scrap through the die channel. To overall maximum cutting force is reduced in all three cases and the decrease is 
approximately linear. A further temperature increase causes thermal deformation of the belt, which is why it is established that temperature $100^{\circ} \mathrm{C}-150^{\circ} \mathrm{C}$ can be taken as an effective value for belt perforation.

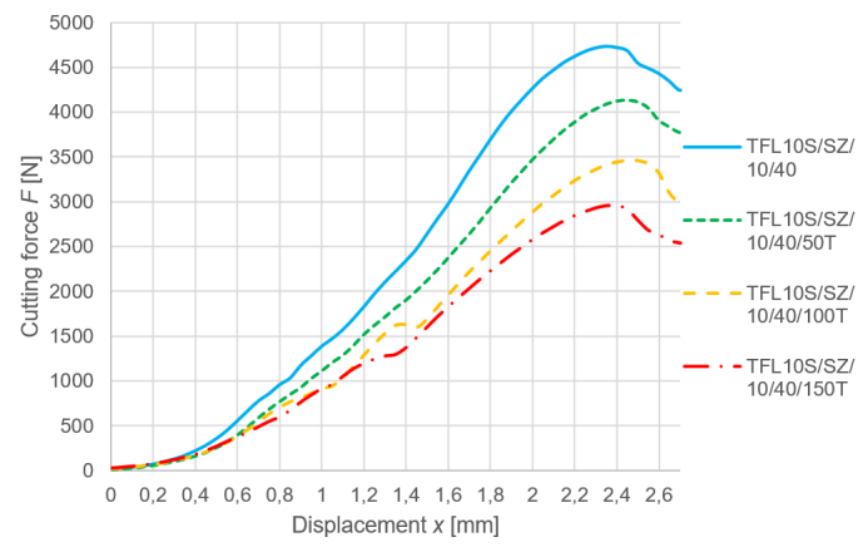

Fig. 11. Comparison of the cutting force during perforation by using the piercing punch with diameter of $10 \mathrm{~mm}$, the tool angle $40^{\circ}$ and the cutting edge towards outside, with various perforation temperature for PolyBelt Nitta TFL10S

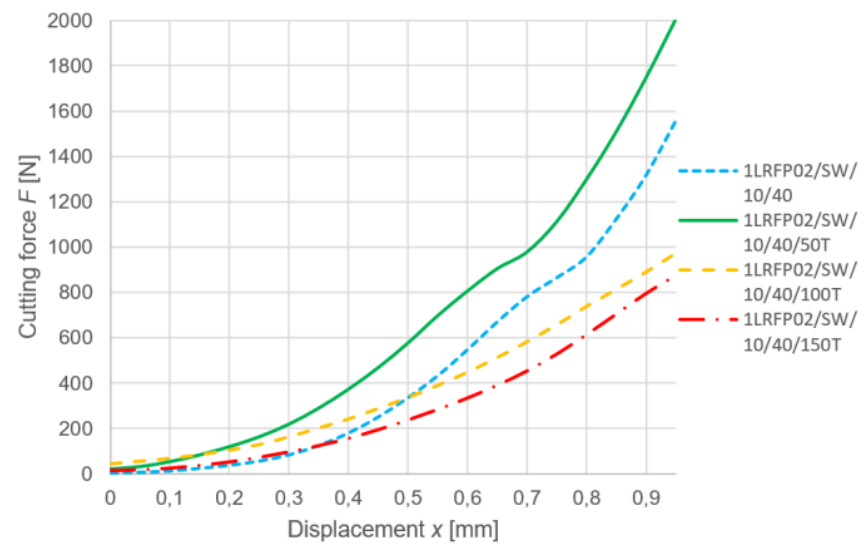

Fig. 12. Comparison of the cutting force during perforation by using the piercing punch with diameter of $10 \mathrm{~mm}$, the tool angle $40^{\circ}$ and the cutting edge towards inside, with various perforation temperature PolySprint Nitta 1LRFP02/W2 IM LSQ

On the other hand not all the material will behave the same way and in some cases increasing the temperature may even cause the increase of the force value. The example is the very thin and elastic conveyor belt made of thermosetting polyurethane 1LRFP02/W2 IM LSQ (Fig. 12). In that case temperature $50^{\circ} \mathrm{C}$ caused the hardening of the belt and as a result an increase of the cutting force. Using higher temperatures gave positive results, but the differences were very small due to high elasticity and almost pure shearing of the belt with compression resistance close to zero. It can be stated, that heating up the working tool has a positive effect in strong rigid polyamide belt perforation, while for light elastic conveyor belts the effect is close to neutral. 
While analysing the perforation process it is very important to consider the quality of the holes along with the cutting force measurement. In Fig. 13. typical defects, which occurred during the perforation process of the conveyor belts are presented.

a)

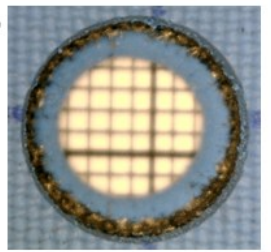

b)

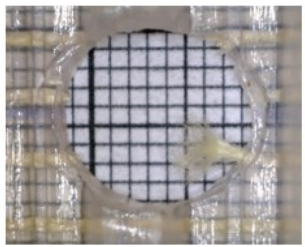

c)

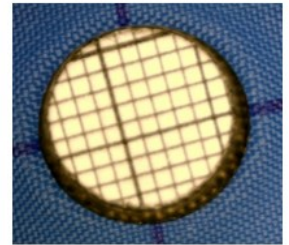

d)

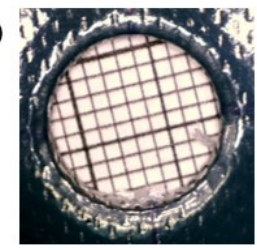

Fig. 13. Defects of perforated belts: a) conicity of the hole, which occurs in thick polyamide belts, b) ovality of the hole for belts with different axial and lateral elasticity and fibre pull-out for belts with fabrics and cords, c) folding of the coating for higher temperatures when cutting edge tilt towards outside, d) deformation of the belt for elastic PVC belts

While perforating thick belts with a polyamide core, the visible difference between entry and exit diameter occurs due the conicity of the hole along with fuzzy edges and uneven side surface of a hole (Fig. 13a and 13c). If the belt was reinforced with a fabric or a cord the pull-out of the fibres occurred (Fig. 13b and 13d). Too high temperature of the piercing punch caused permanent thermal deformation for elastic PCV belt (Fig. 13d) or folding of the coating along the edge of a hole (Fig 13c). Significant differences in the elasticity in longitudinal and traverse direction for light belts caused high roundness deviation whose result was an oval hole (Fig. 13b and 13d). The above-mentioned defects can be minimalized or eliminated by properly chosen perforation process parameters. For example, heating up the piercing punch, as well as using the hollow piercing punch with the cutting edge towards outside, almost eliminated the conicity of the hole. That is why extended research of these phenomena is necessary in order to develop the punching of the vacuum conveyor belts and specify effective process parameters (velocity, temperature, tool geometry) for different types of belts.

\section{Conclusions}

Based on the results, regardless of the belt type, the lowest value of the cutting force is necessary, when we use the piercing punch with the reducer plate and the cutting edge towards outside. By decreasing the tool angle, the fall of the cutting force is visible, but it is not proportional. The tool angle $30^{\circ}$ is the effective one, because it is the compromise between the cutting force and the durability of the cutting edge. It was very visible that elastic belts are much more sensitive to the wear of the blade than strong polyamide belts, which is caused by the different cutting - compressing ratio of the perforation process. We can also conclude that for elastic belts the influence of velocity is insignificant, while for polyamide belts higher speed may reduce the cutting force. By increasing the temperature of the piercing punch it is possible to lower the cutting force and improve the quality of the holes (cylindrical holes) for polyamide belts, but for elastic thermosetting polyurethane belts $50^{\circ} \mathrm{C}$ may even harden the material and increase the cutting force or may cause the coating deformation. Increasing the temperature will affect mainly the compression phase, which is why the differences are visible mainly in the second stage of perforation (compressing scrap material inside the hollow piercing punch or pushing it through the piercing die channel). The defects discussed in this paper can be removed by properly choosing the tools and parameters of the perforation process, and this is why the research is so significant for the industry. 
The presented results have been obtained in the course of realising the project "Opracowanie innowacyjnej technologii systemu precyzyjnej mechanicznej perforacji pasów do transportu podciśnieniowego i sterowania optycznego - systemu automatyzujacego proces produkcyjny pasów transportowych", which is funded by Wilhelm Herm. Müller Polska Sp. z.o.o and Polska Agencja Rozwoju Przedsiębiorczości (PARP).

\section{References}

1. M. Hardygóra. Taśmy przenośnikowe. Wydawnictwo Naukowo-Techniczne, Chapter 1 and 2, Warszawa (1999)

2. L. Gładyszewicz. Przenośniki Taśmowe - teoria $i$ obliczenia. Wydawnictwo Politechniki Wrocławskiej (2003)

3. Wilhelm Herm. Müller, Nitta Industries - polish catalog. In: www.whm.pl (Access date: 06.07.2017)

4. R. Perneder, I. Osborne. Handbook Timing Belts - Principles, Calculations, Applications. Springer (2012)

5. Optibelt. Technical manual polyurethane timing belts - catalog. In: www.optibeltusa.com (Access date: 06.07.2017)

6. Habasit. HabaSYNC Timing Belts - product media No. 4107. In: www.habasit.com (Access date: 06.07.2017)

7. J. Sheikh-Ahmad. Machining of polymer composites. Springer (2009)

8. G. Chryssolouris. K. Salonitis. Fundamentals of laser machining of composites, In: Machining Technology for Composite Materials, Chapter 10, 266-287 (2011)

9. R. Negarestani, L. Li. Laser machining of fibre-reinforced polymeric composite materials. In: Machining Technology for Composite Materials, Elsevier, Chapter 11, 288-308 (2011)

10. D. Krajcarz. Comparison Metal Water Jet Cutting with Laser and Plasma Cutting. Procedia Engineering 69, 838-843 (2014)

11. A. Skoczylas, Analiza porównawcza procesu cięcia wiązka laserowa $i$ strumieniem wodno- ściernym. Postępy Nauki i Techniki 8, 121-128 (2011)

12. D. Krajcarz, S. Spadło. Wpływ wybranych parametrów procesu cięcia struga wodnościerna na odchyłkę okrąłłości otworów cylindrycznych. Mechanik 01/2017, 64-65 (2017)

13. F. Lachaud, R. Piquet, F. Collombet, L. Surcin. Drilling of composite structures. Composite Structures 52, 511-516 (2001)

14. T. Leppert, T. Paczkowski, R. Polasik, D. Serwacki. Delaminacja materiału kompozytowego włóknistego podczas wykonywania otworów. Mechanik 10/2016, 1422-1423 (2016)

15. I. Suchy. Handbook of Die Design. McGraw-Hill Companies (2006)

16. H.Y. Chan, A.B. Abdullah, Z. Samad. Precision punching of hole on composite panels. Indian Journal of Engineering \& Material Sciences 22, 641-651 (2015)

17. F. Lambiase, M. Durante. Mechanical behavior of punched holes produced on thin glass fiber reinforced plastic laminates. Composite Structures 173, 25-34 (2017)

18. M.S.M. Zain, A.B. Abdullah, Z. Samad. Effect of puncher profile on the precision of punched holes on composite panels. International Journal Of Advanced Manufacturing Technology 89, 3331-3336 (2017) 